www.jmscr.igmpublication.org

Impact Factor 5.84

Index Copernicus Value: 71.58

ISSN (e)-2347-176x ISSN (p) 2455-0450

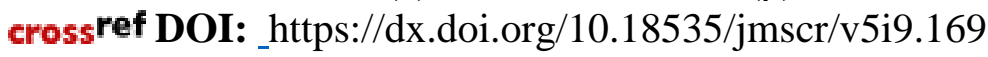

Journal Of Medical Science And Clinical Research

\title{
A study of Primary Hand Osteoarthritis and Association with Knee Arthritis in Rural Population of UPUMS, Saifai, Etawah
}

\author{
Authors \\ Dr Swati Srivastava ${ }^{1}$, Dr Manish Gupta ${ }^{2}$, Dr Manoj Kumar ${ }^{3}$, Dr P S Singh ${ }^{4}$, \\ Dr Ejaz Ahmad 5 , Dr (Brig) T. Prabhakar ${ }^{6}$ \\ ${ }^{1}$ Assistant Professor, Dept. of Anaesthesiology, Critical Care \& Pain, UPUMS, Saifai, Etawah \\ ${ }^{2}$ Assistant Professor, Dept. of General Medicine, UPUMS, Saifai, Etawah \\ ${ }^{3}$ Professor, Dept. of General Medicine, UPUMS, Saifai, Etawah \\ ${ }^{4}$ Professor, Dept. of General Medicine, RML Hospital, Lucknow \\ ${ }^{5}$ Post Graduate trainee, Dept. of General Medicine, UPUMS, Saifai, Etawah \\ ${ }^{6}$ Vice Chancellor, UPUMS, Saifai, Etawah \\ Corresponding Author \\ Dr Manish Gupta \\ Assistant Professor, Dept. of General Medicine, UPUMS, Saifai, Etawah
}

\begin{abstract}
Objectives: To investigate the prevalence and pattern of osteoarthritis $(O A)$ of the hand joints in patients presenting with hand symptoms and also to find out whether knee osteoarthritis has an association with hand osteoarthritis.

Methods: This study included patients who presented with hand symptoms of arthritis in Pain clinic and Medicine out-patient department of Uttar Pradesh University of Medical Sciences, Saifai, Etawah. We also looked for hand symptoms in those patients who were established cases of knee OA.

Hand osteoarthritis was diagnosed using European League Against Rheumatism (EULAR) Recommendations which includes plain radiograph of hand and clinical examination. For supporting the diagnosis we did routine blood tests. For studying the pattern of hand osteoarthritis other relevant data including age, sex, occupation, handedness and body mass index (BMI) were sought for.

Results: Hand OA is a heterogeneous, age- and gender-dependent disorder, occurring more frequently in women over 50 years of age. Of the total patients $(n=200)$ investigated $29 \%$ of the patients had hand symptoms. Of all patients only $20 \%$ were confirmed as cases of hand OA by EULAR criteria. $33 \%$ of the knee OA patients also had hand OA irrespective of their hand symptoms. A history of heavy manual labour or a repetitive use of the hand was shown to have higher incidence. Other variables such as BMI and handedness may also play a role.

Conclusions: Elderly age, female sex, high BMI and increasing usage of hand showed an increased development of hand OA. The presence of knee OA at baseline may predict an increased risk of hand OA.
\end{abstract}

\section{Introduction}

Life expectancy has increased over the last decades. However, many people reach old age with increasing chronic pain and disability. In a recent United Kingdom survey, the incidence of self reported pain was $50 \%$, or $46.5 \%$ when 
adjusted to the whole UK population. ${ }^{(1)}$ The three most common causes of chronic pain are musculoskeletal disorders, neuropathic disorders and tumours. ${ }^{(2)}$ The reported prevalence of hand or wrist pain varies between $3 \%$ and $26 \%$ of the general population. ${ }^{(3-5)}$ Rheumatoid arthritis, other types of chronic arthritis, osteoarthritis, carpal tunnel syndrome, different forms of tendinitis in the hand and wrist, referred pain from the neck or shoulder, diabetes, other peripheral neuropathies, fractures in the hand and wrist, fibromyalgia, stroke, thyroid disease, gout, Parkinson's disease, obesity, manual occupation, age, and sex are all potentially related to hand pain or hand disability. ${ }^{(3,8)}$ However, the interrelations of most of these factors have not been explored. Moreover, most of these data either pertain to western world or are taken from urban population. Our aim in this study was therefore to investigate the prevalence of hand pain in the elderly, contribution of several potential determinants to these problems and its association with knee osteoarthritis in rural population where lifestyle and nature of work is quite different from urban setup.

Plain radiographs are the initial method of choice to image the hands, as they are widely available, cheap and reproducible. The characteristic radiological features of osteoarthritis include joint space narrowing, osteophytes, sclerosis and deformity. It is not clear whether any or all these features are truly indicative of osteoarthritis. Osteophytosis, without joint space narrowing, can be present even after several years of follow-up, raising the question of whether this condition should be addressed as osteoarthritis. ${ }^{(9)}$ Radiographic features of osteoarthritis are often seen in the hands, especially in elderly patients, in the absence of symptoms, and so may represent age-related changes. ${ }^{(10)}$ Kessler et al. ${ }^{(11)}$ suggested a hand scale for osteoarthritis in which radiological osteoarthritis is defined only when joint space narrowing is present. To determine the nature and severity of osteoarthritis in hand joints, several standardized qualitative scoring methods can be used, including those described by Kellgren and Lawrence, ${ }^{(12)}$ many individual features can be scored, but none of these methods distinguishes between features of damage and repair. The question arises as to which joints of the hands should be scored. Usually, DIPs, PIPs and first CMCs are assessed in published methods. Whether or not metacarpophalangeal joints (MCPs) should be included is not clear. Further, it has not been clarified whether erosive osteoarthritis is a distinct disease entity or an aggressive variant of hand osteoarthritis. Verbruggen and Veys ${ }^{(13,14)}$ developed a scoring method in which erosive osteoarthritis is addressed. Currently, no validated quantitative scoring method is available for hand osteoarthritis. It is not clear which feature should be addressed, and with regard to joint space width, it is unclear which part of the inter-bone distance should be measured and how. Osteophytes have been quantified by microfocal radiographic techniques, but this method is not widely available.

\section{Material and Methods}

After obtaining institutional ethics committee approval, this hospital based, cross sectional, observational, non-randomised study was started. Patients of knee osteoarthritis irrespective of hand symptom \& patients above 40 years of age who presented with hand symptoms attending pain clinic and general medicine outdoor clinic of UPUMS, Saifai were included in this study. Patients with history of acute mechanical injury in hand and those with secondary osteoarthritis or inflammatory disorders were excluded.

Written informed consent was taken from all patients. Symptoms of hand osteoarthritis were considered positive if there was complaint of pain on usage with only mild morning or inactivity stiffness, affecting just one or a few joints at any one time. Intermittent symptoms were considered positive if they targeted characteristic sites (distal and proximal interphalangeal joints, thumb base, index and metacarpophalangeal joints). Hand examination was done in all patients. Age, sex, 
positive family history, occupational usage, and obesity were specifically sought for in history for purpose of etiological co-relation. Family history was considered positive if any of patients' first or second degree relative suffered from osteoarthritis after the age of 40 years. The basic questionnaire included questions about the participants' present and previous occupations involving exposure to (a) lifting or carrying heavy objects (b) stooped, twisted, or otherwise awkward work posture $(c)$ vibration of the whole body or the use of vibrating equipment $(d)$ continuously repeated series of movements, and (e) paced work (working speed determined by a machine). The subject was considered to have been exposed to one of the above if they reported it either in the most recent or present occupation.

A postero-anterior plain radiograph of both hands on a single film/field of view was advised to all these patients. Features such as joint space narrowing, osteophyte, subchondral bone sclerosis and subchondral cyst were looked for. The radiographs were graded by a different investigator who did not know the earlier history and physical findings.

Blood tests were not ordered for all patients. It was undertaken only to exclude coexistent disease. In patients, who had marked inflammatory symptoms and/or signs, especially involving atypical sites, blood tests were undertaken to screen for additional inflammatory response, and if, found positive, these patients were excluded from study.

Results were tabulated in Microsoft office excel worksheet and expressed continuously distributed variable, and in absolute numbers and percentages for discrete variables.

Distribution of risk factors were compared using the $\mathrm{x} 2$-test (categorical variables). Binary logistic regression models were used to estimate the association of hand osteoarthritis with age, sex, BMI, occupation, knee osteoarthritis, diabetes mellitus, family history, etc. The analyses were performed with the SPSS (version 16.0) program.

\section{Result}

In this study, we analyzed 200 patients $(n=200)$ and evaluated them for risk factors associated with hand OA. Table 1 enumerates our observations whereas table 2 shows the distribution of hand examination findings in study popultion. We observed that majority of the patients were between 40 to 49 years of age $(45.53 \%)$ of which females constituted $52.80 \%$. Females of more than 40 years of age had either hand symptom or knee osteoarthritis. There was no history suggestive of secondary osteoarthritis. Similar criteria was also applied to our male study population. Most of the patients had normal BMI (156/200). 30 patients were in pre-obese condition (BMI: 25-29.99 $\mathrm{kg} / \mathrm{m}^{2}$ ). Obesity (BMI >30) was found in 11 patients. 57 out of 200 patients had family history of osteoarthritis (knee, hand \& hip). 44 patients had occupational risk factors.

Knee osteoarthritis was present in 124 patients, irrespective of their hand symptoms and diabetes mellitus was present 32 patients. Knee osteoarthritis was considered positive on the basis of suggestive history and $x$ ray of knee. Diabetes mellitus was considered positive if patient had fasting blood sugar $=>126 \mathrm{mg} / \mathrm{dl}$ or $\mathrm{Hba} 1 \mathrm{c}=>$ $6.5 \%$ or patient is a diagnosed case of DM, irrespective of duration.

In this study hand X-ray PA view was considered as the investigation of choice for diagnosing hand osteoarthritis and $20 \%$ of patients $(n=80)$ were found positive for hand osteoarthritis.

When other variables were compared to radiologically positive hand osteoarthritis, following variables were found to be associated significantly like age of patient $(\mathrm{p}=<0.0000)$, female sex $(\mathrm{p}=0.016), \quad \mathrm{BMI}(\mathrm{p}=0.0000)$, family history of $\mathrm{OA}(\mathrm{p}=0.0194)$, Bouchard's Node and Heberden's Node $(\mathrm{p}=0.0000)$, knee OA $(\mathrm{p}=0.0000)$, involvement of thumb base $(\mathrm{p}=0.001)$, Diabetes mellitus $(\mathrm{p}=0.001)$ etc.

We further did a binary logistic regression [Table 3] and found that age and occupational risk is associated significantly with risk of development of hand osteoarthritis $(\operatorname{sig}<0.05)$. Age, BMI, 
family history of osteoarthritis and occupational risk increases chances of hand osteoarthritis (exp $\beta>1$ ). Bouchard's node, Heberden's node and base of thumb involvement were also as associated with increased risk of hand osteoarthritis (exp $\beta>1)$

\begin{tabular}{|c|c|c|c|c|}
\hline Table 1: & & & & \\
\hline & & positive & Negative & $\chi^{2}$ \\
\hline & $40-49$ & 1 & 100 & \\
\hline$\triangle G F(Y F A R S)$ & $50-59$ & 6 & 50 & \\
\hline AUE(YEAKS) & $60-69$ & 11 & 10 & $\begin{array}{c}\mathrm{d}=3 \\
-\leq 0001\end{array}$ \\
\hline & $70-79$ & 19 & 4 & \\
\hline SEX & Male & 21 & 84 & $\chi^{2}=5.74$ \\
\hline SEX & Female & 55 & 40 & $\mathrm{df}=1 \quad \mathrm{p}=0.016$ \\
\hline ГА М У ULTODУ & Present & 22 & 42 & $\chi^{2}=6.57$ \\
\hline FAMILY HISIOKY & Absent & 41 & 95 & $\mathrm{df}=1 \quad \mathrm{p}=0.01$ \\
\hline & $<18$ & 0 & 4 & \\
\hline $\operatorname{RMI}\left(\mathrm{KG} / \mathrm{m}^{2}\right)$ & $18-24.99$ & 34 & 126 & $\chi \begin{array}{l}\chi=01.50 \\
\mathrm{~d} f-1\end{array}$ \\
\hline $\operatorname{BIVI}(\mathrm{K} \mathrm{U} / \mathrm{m})$ & $25-29.99$ & 20 & 08 & $\begin{array}{c}\mathrm{d}=1 \\
-\leq 0001\end{array}$ \\
\hline & $>30$ & 06 & 2 & \\
\hline OCCUPATIONL & PRESENT & 21 & 38 & $\chi^{2}=4.88$ \\
\hline FACTOR & ABSENT & 44 & 97 & $\mathrm{df}=1 \quad \mathrm{p}=0.027$ \\
\hline HAND CVMPTOMS & Present & 29 & 75 & $\chi^{2=5.36}$ \\
\hline HAND S YMIFTUMS & Absent & 33 & 63 & $\mathrm{df}=1 \quad \mathrm{p}=0.020$ \\
\hline UANDFDNECC & Right & 65 & 131 & $\chi^{2}=6.82$ \\
\hline HANDEDNESS & Left & 1 & 3 & $\mathrm{df}=1 \quad \mathrm{p}=0.007$ \\
\hline DAN OM МОУГMГNT & PRESENT & 26 & 42 & $\chi^{2}=1.56$ \\
\hline PAIN ON MOVEMENT & ABSENT & 43 & 89 & $\mathrm{df}=1, \quad \mathrm{p}=0.212$ \\
\hline KNEE & PRESENT & 66 & 71 & $\chi^{2}=42.51$ \\
\hline OSTEOARTHRITIS & ABSENT & 9 & 54 & $\mathrm{df}=1, \mathrm{p}=<0.001$ \\
\hline DUA RETES MEL UTUS & PRESENT & 23 & 08 & $\chi^{2}=49.60$ \\
\hline DIABEIES MELLIIUS & ABSENT & 31 & 138 & $\mathrm{df}=1, \mathrm{p}=<0.001$ \\
\hline BOUCHARD'S NODE \& & PRESENT & 22 & 02 & $\chi^{2}=94.23$ \\
\hline HEBERDEN'S NODE & ABSENT & 44 & 132 & $\mathrm{df}=1, \quad \mathrm{p}=<0.001$ \\
\hline THUMB $\quad$ BASE & PRESENT & 35 & 9 & $\chi^{2}=96.21$ \\
\hline INVOLVEMENT & ABSENT & 17 & 139 & $\mathrm{df}=1, \mathrm{p}=<0.001$ \\
\hline EROSIVE CHANGES & PRESENT & 09 & 1 & $\chi^{2}=46.30$ \\
\hline & ABSENT & 63 & 127 & $\mathrm{df}=1, \quad \mathrm{p}=<0.001$ \\
\hline ECP/CDP L EVEI & HIGH & 15 & 15 & $\chi^{2}=12.71$ \\
\hline ESR/CRP LEVEL & NORMAL & 43 & 127 & $\mathrm{df}=1, \mathrm{p}=0.0003$ \\
\hline $\begin{array}{lll}\text { SERUM } & \text { URIC } & \text { ACID }\end{array}$ & HIGH & 2 & 5 & $\chi^{2}=3.96$ \\
\hline LEVEL & NORMAL & 75 & 118 & $\mathrm{df}=1, \quad \mathrm{p}=0.718$ \\
\hline & & & & \\
\hline
\end{tabular}

Table-2 Distribution of hand examination findings in study population

\begin{tabular}{|l|c|c|c|}
\hline \multirow{2}{*}{ HANDEDNESS } & Right & 193 & $96.36 \%$ \\
\cline { 2 - 4 } & Left & 07 & $3.64 \%$ \\
\hline Pain On Movement & Present & 83 & $41.62 \%$ \\
\cline { 2 - 4 } & Absent & 117 & $58.38 \%$ \\
\hline Involvement Of Thumb Base & Present & 46 & $22.62 \%$ \\
\cline { 2 - 4 } & Absent & 154 & $77.38 \%$ \\
\hline \multirow{2}{*}{ Hand Symptom } & Present & 119 & $59.21 \%$ \\
\cline { 2 - 4 } & Absent & 81 & $40.79 \%$ \\
\hline $\begin{array}{l}\text { Node : } \\
\text { Heberden's / Nodebouchard's }\end{array}$ & Present & 21 & $10.06 \%$ \\
\cline { 2 - 4 } & Absent & 179 & $89.94 \%$ \\
\hline
\end{tabular}


Table 3: Binary logistic regression analysis Variables in the Equation

\begin{tabular}{|l|c|c|c|c|c|c|}
\hline & B & S.E. & Wald & df & Sig. & Exp(B) \\
\hline SEX & -.670 & .506 & 1.754 & 1 & .185 & .511 \\
AGE & .184 & .041 & 19.748 & 1 & .000 & 1.202 \\
HEIGHT & .074 & .127 & .337 & 1 & .561 & 1.077 \\
BW & -.100 & .152 & .432 & 1 & .511 & .905 \\
BMI & .519 & .365 & 2.029 & 1 & .154 & 1.681 \\
FAMILY H/O OA & .883 & .523 & 2.846 & 1 & .092 & 2.418 \\
OCCUPATION RISK & 1.593 & .579 & 7.562 & 1 & .006 & 4.919 \\
HANDEDNESS & -1.086 & 2.043 & .283 & 1 & .595 & .337 \\
HAND SYMPTOM & .093 & .737 & .016 & 1 & .900 & 1.097 \\
PAIN ON MOVEMENT & -.468 & .759 & .380 & 1 & .537 & .626 \\
B.NODE/H.NODE & 1.166 & 1.023 & 1.299 & 1 & .254 & 3.210 \\
KNEE OA & -.979 & .787 & 1.550 & 1 & .213 & .375 \\
THUMB BASE & 1.742 & .673 & 6.707 & 1 & .010 & 5.708 \\
EROSIVE CHANGES & 17.003 & $8.599 \mathrm{E} 3$ & .000 & 1 & .998 & $2.423 \mathrm{E} 7$ \\
DM & .907 & .586 & 2.396 & 1 & .122 & 2.477 \\
ESR/CRP & -.165 & .847 & .038 & 1 & .846 & .848 \\
RF & -18.869 & $7.024 \mathrm{E} 3$ & .000 & 1 & .998 & .000 \\
URIC ACID & 1.955 & 1.630 & 1.438 & 1 & .230 & 7.064 \\
Constant & -29.955 & 19.894 & 2.267 & 1 & .132 & .000 \\
\hline
\end{tabular}

\section{Discussion}

There is no absolute clinical, radiological, or pathological standard against which epidemiological definitions of hand osteoarthritis (OA) can be tested. ${ }^{(15)}$ In this study, therefore, we compared the associations of clinical and radiographic measures of the disease with reported symptoms and with $\mathrm{OA}$ of the knee, the large joint most often affected in association with hand OA. Clinical and radiographic features correlated with each other and were associated with symptoms to a similar degree. Moreover, when analyzed in combination they were only marginally better at predicting symptoms than when tested individually. The radiographs were graded by a different investigator who did not know the earlier history and physical findings. If anything, this bias would exaggerate the merits of clinical assessment. However, their conclusion was based on the ability of clinical and radiological features to discriminate between patients with hand OA and patients attending a rheumatology clinic with other causes of hand pain, mainly rheumatoid arthritis. In the general population, where the prevalence of $\mathrm{OA}$ is much higher than that of other arthritis, accurate diagnosis depends more on distinguishing OA cases from people with no joint disease whatsoever. For this purpose, it appears that $\mathrm{x}$ ray must be more useful than physical examination. This observation is unlikely to be explained by differences in the reproducibility with which clinical and radiographic features were assessed.

The definition of pain which we used in our study differed from that used in the ACR study, which enquired about pain on most days for at least one month during the previous year. One previous population-based study $^{(16)}$ has examined the association between clinical and radiographic features of hand OA, as well as correlating hand 


\section{JMSCR Vol||05||Issue||09||Page 28366-28374||September}

involvement with knee disease. Assessments were made on 6584 men and women in Zoetermeer, The Netherlands, and strong relationships were reported between radiographic hand and knee OA. The presence of Heberden's nodes was also found to be highly predictive of radiographic OA at these two sites, although the overall prevalence of clinical signs of OA was substantially lower than that of radiographic OA. In contrast to the American College of Rheumatology Study ${ }^{(17)}$, our study concluded that radiography is the method of choice for the confirmation of hand $\mathrm{OA}$ in populations or subgroups within populations. Our results support this notion, but suggest that clinical examination might be an acceptable, albeit less preferable, option.

Table 4: Propositions and strength of recommendation (SOR) - order according to topic (risk factors, clinical, subsets, differential diagnosis, images and laboratory tests)

\begin{tabular}{|c|c|c|c|}
\hline No. & Proposition & LoE & SOR $(95 \%$ C Cl) \\
\hline 1 & $\begin{array}{l}\text { Risk factors for HOA include female sex, increasing age over 40, menopausal status, family history, obesity, higher } \\
\text { bone density, greater foream muscle strengut, joint laxity, prior hand injury and occupation or recreation-related } \\
\text { usage. }\end{array}$ & $\|b-\| b$ & 69 (54 to 84) \\
\hline 2 & $\begin{array}{l}\text { Typical symptoms of HOA are pain on usage and only mild morning or inactivity stitthess affecting just one or } \\
\text { a few joints at any one time; symptoms are often intermittent and target characteristic sites (DPIS, PIPJs, } \\
\text { thumb base, index and middle MCPJS). With such typical features, a confident clinical diagnosis can be made } \\
\text { in adults aged over 40. }\end{array}$ & $\| \mathrm{b}$ & 85 (77 to 92) \\
\hline 3 & $\begin{array}{l}\text { Clinical hallmarks of HOA are Heberden and Bouchard nodes and/or bony enlargement with or without deformity } \\
\text { (eg, lateral deviation of PPJs, subluxation and adduction of thumb base) affecting characteristic target joints } \\
\text { (DIPJs, PIPJS, thumb base and index and middle MCPJs). }\end{array}$ & |b-IV & $80(69$ to 90$)$ \\
\hline 4 & $\begin{array}{l}\text { Functional impaiment in hand } O A \text { may be as severe as in heumatoid arturitis. Function should be careftully } \\
\text { assessed and monitored using validated outcome measures. }\end{array}$ & 116 & $57(42$ to 73$)$ \\
\hline 5 & $\begin{array}{l}\text { Patients with polyarticular HOA are at increased risk of knee OA, hip OA and OA at other common target sites } \\
\text { (generalised OA) and should be assessed and examined accordingly. }\end{array}$ & $\|a-\| b$ & $77(62$ to 92) \\
\hline 6 & $\begin{array}{l}\text { Recognised subsets with difterent risk factors, associations and outcomes (requiring different assessment and } \\
\text { management) include IPJ OA (with or without nodess, thumb base OA and erosive OA. Each may be symptomatic } \\
\text { or asymptomatic. }\end{array}$ & $\|a-\| b$ & $68(56$ to 79$)$ \\
\hline 1 & $\begin{array}{l}\text { Erosive hand OA tarrgets IPJs and shows radiograahic subchondral erosion, which may progress to marked bone } \\
\text { and Cartilage attrition, instability and bony ankylosis. Typically it has an abrupt onset, marked pain and functional } \\
\text { impaiment, inflammatory symptoms and signs (stitfness, soot tissule swelling, ervthaeema, paraesthesiae), mildly } \\
\text { elevated CRP levels, and a worse outcome than non-erosive IPJ OA. }\end{array}$ & $\|a-\| b$ & $87(81$ to 93 ) \\
\hline 8 & $\begin{array}{l}\text { The differential diagnosis for HOA is wide. The commonest conditions to consider are psoniatic arthritis (which may } \\
\text { target DPJJs or affect just one ray), heumatoid athritis (mainly targeting MCPJs, PPIJs, wrists), gout (which may } \\
\text { superimpose on pre-existing HOA), and haemochromatosis (mainly targeting MCPSS, wrists). }\end{array}$ & $\mid b-\| b$ & 81 (73 to 89) \\
\hline 9 & $\begin{array}{l}\text { Plain radiographs provide the gold standard for morphological assessment of HOA. A posteroanterior radiograph of } \\
\text { both hands on a single film/field of view is adequate for diagnosis. Classical features are joint space narrowing, } \\
\text { osteophyte, subchondral bone sclerosis and subchondral cyst, and subchondral erosion occurs in erosive hand OA. } \\
\text { Further imaging modalities are seldom indicated for diagnosis. }\end{array}$ & $\|b-\| b$ & $87(81$ to 93 ) \\
\hline 10 & $\begin{array}{l}\text { Blood tests are not required for diagnosis of HOA but may be required to exclude coexistent disease. In a patient } \\
\text { with HOA who has marked inflammatory symptoms andlor signs, especially involving atypical sites, blood tests } \\
\text { should be undertaken to screen for additional inflammatory arthritides. }\end{array}$ & $\|b-\| b$ & $78(63$ to 92) \\
\hline
\end{tabular}

Radiographic assessment of OA is currently undergoing a reappraisal. We used the Kellgren and Lawrence classification features for diagnosis joints, but this system has several deficiencies. ${ }^{(17)}$ They include inconsistent descriptions of the criteria by which grades are assigned, uncertain 
reproducibility, and overemphasis on isolated osteophyte formation. Recent epidemiological studies of hand OA have examined the reproducibility with which component radiographic features (joint space narrowing, osteophytes, sclerosis, cysts, deformity and collapse) are assessed, ${ }^{(18,19)}$ and have led to the proposal of a new set of standard radiographs in which these features are graded separately. ${ }^{(20)}$ The reproducibility of grading with these more explicit standards is greater, both within and between observers, than that using the Kellgren and Lawrence scales. Such improvements should further enhance the value of radiological assessment. In, our findings in middle-aged women suggest that radiology is more useful than physical examination in the classification of hand OA for epidemiological studies in the general population, and that assessment should include examination of the thumb carpo-metacarpal joints as well as the interphalangeal joints. If radiographs are available, physical examination adds little. However, if radiographs cannot be obtained, clinical evaluation of the interphalangeal joints provides a good alternative index of disease. Hand OA is a multifactorial age-dependent degenerative condition, and in the our study, unsurprisingly, age was found to be the most powerful factor in the development of hand OA $(p=<0.001)$. This concurs with findings of Livshits et al ${ }^{(21)}$, who reported that age contributed $72.8 \%$ to the total variance of hand OA. BMI is the most commonly used measurement of obesity or underweight, as weight and height are easy to measure. It does not, however, take into account the proportion of weight related to increased muscle mass or the fat distribution. Individuals with similar BMIs can also vary considerably in their intra-abdominal fat, a factor found to be associated with morbidity ${ }^{(21)}$ and mortality ${ }^{(22)}$. In our study high BMI is a risk factor for development of hand osteoarthritis $(p=<0.001)$.

The main findings which emerge from our study are that osteo-arthrosis when present usually affects many joints and has a rather characteristic pattern of joint involvement. Pattern of joint involvement, severity of changes in the individual joints and number of joints affected, are all more pronounced in females than in males. These findings suggest that a major factor in the causation of osteo-arthrosis may be some sexlinked metabolic characteristic. A high prevalence of osteo-arthrosis in the distal interphalangeal joints in females has long been recognized in the form of Heberden's nodes, and a clear association between these nodes and radiological signs of osteo-arthrosis in multiple joints has been demonstrated in both sexes but especially in females. In our study we also support this finding $(\mathrm{p}=<0.001)$. Stecher (1955) has suggested that the factor responsible for Heberden's nodes is inherited as a single autosomal gene dominant in females and possibly recessive in males. This factor need not be specific for Heberden's nodes in particular, but may be a tendency to osteoarthrosis in general, which expresses itself more strongly in the fingers of females because of the special mechanical stresses to which their fingers are exposed in domestic work.

In males, the basic pattern of osteo-arthrosis is modified to a great extent by occupational stresses and also by individual episodes of trauma though history of trauma was exclusion criteria from our study, so that in this sex environmental mechanical factors play an important part in determining both the severity and the site of osteoarthrosis. The effect of obesity is apparent in both sexes and is mainly associated with an excess of osteoarthrosis in the weight-bearing joints suggesting a mechanical effect, but in males obesity is also associated with an excess of osteoarthrosis of the distal interphalangeal joints and the general pattern of osteo-arthrosis in obese males approximates to that seen in the total females. This is not due to occupational stresses since the occupational spectrum of the obese males did not differ from that of the total males. A hereditary tendency to osteo-arthrosis has been encountered in animals other than man, for example, in certain inbred strains of mice. It 
closely simulates its human counterpart in anatomical features, in its relationship to postural characteristics, and in its occurrence in older age groups. It may be modified by external factors, such as a high fat diet in susceptible strains, though it is little affected by such diet in other strains.

Osteoarthritis is a metabolically active, dynamic process that involves all joint tissues (cartilage, bone, synovium /capsule, ligaments and muscle). Key pathological changes include localised loss of articular (hyaline) cartilage and remodelling of adjacent bone with new bone formation (osteophyte) at the joint margins. This combination of tissue loss and new tissue synthesis supports the view of osteoarthritis as the repair process of synovial joints. A variety of joint traumas may trigger the need to repair, but once initiated all the joint tissues take part, showing increased cell activity and new tissue production. In general, osteoarthritis is a slow but efficient repair process that often compensates for the initial trauma, resulting in a structurally altered but symptomfree joint. In some people, however, either because of overwhelming insult or compromised repair potential, the osteoarthritis process cannot compensate, resulting in continuing tissue damage and eventual presentation with symptomatic osteoarthritis or 'joint failure'. This explains the extreme variability in clinical presentation and outcome, both between individuals and at different joint sites. The specific targeting of osteoarthritis for certain joints remains unexplained in our study like base of thumb involvement $(\mathrm{p}=<0.001)$ etc., but one hypothesis suggests an evolutionary fault where joints that have most recently altered are biomechanically under designed and thus more often fail. The cause of joint pain in osteoarthritis is not well understood. Estimates suggest that up to 8.5 million people in the UK are affected by joint pain that may be attributed to osteoarthritis (Arthritis Care 2004). Population estimates of the prevalence of joint symptoms depend heavily on the specific definition used, but there is general agreement that the occurrence of symptoms is more common than radiographic osteoarthritis in any given joint among older people. This may be due to joint pain arising from causes other than osteoarthritis (for example bursitis, tendonitis) and differing radiographic protocols.

In adults 45 years old and over, the most common site of peripheral joint pain lasting for more than one week in the past month is in the knee (19\%) and the highest prevalence of knee pain is among women aged 75 and over (35\%). Global disability is also high among those reporting isolated knee pain. In adults aged 50 years old and over, 23\% report severe pain and disability. One-month period prevalence of hand pain ranges from $12 \%$ in adults 45 years and over to $30 \%$ in adults 50 years and over and is more common in women than men, increasing in prevalence in the oldest age groups. Radiographic rather than symptomatic hand osteoarthritis is frequently the subject of research. For the development of new therapies, however, more insight into symptomatic osteoarthritis is especially relevant. Important questions to be investigated are the prevalence of symptomatic hand osteoarthritis, the relation of symptomatic hand osteoarthritis to radiographic hand osteoarthritis and the functional impact of hand osteoarthritis. Furthermore, insight into potentially modifiable risk factors and the disease process and outcome is needed.

\section{References}

1. Elliott AM, Smith BH, Penny KI, Smith WC, Chambers WA. The epidemiology of chronic pain in the community. Lancet 1999; 9:1248-52.

2. Wilder-Smith $\mathrm{OH}$, Mohrle JJ, Dolin PJ, Martin NC. The management of pain in Switzerland: a comparative survey of Swiss medical specialists treating chronic pain. Eur J Pain 2001;5:285-98.

3. Palmer KT. Regional musculoskeletal conditions: pain in the forearm, wrist and hand. Best Pract Res Clin Rheumatol 2003;17:113-35. 
4. Palmer KT, Syddall H, Cooper C, Coggon D. Smoking and musculoskeletal disorders: findings from a British national survey. Ann Rheum Dis 2003;62:33-6.

5. Urwin $M$, Symmons $D$, Allison $T$, Brammah T, Busby $\mathrm{H}$, Roxby $\mathrm{M}$, et al. Estimating the burden of musculoskeletal disorders in the community: the compareative prevalence of symptoms at different anatomical sites, and the relation to social deprivation. Ann Rheum Dis 1998;57: 649-55.

6. Eberhardt KB, Fex E. Functional impairment and disability in early rheumatoid arthritis-development over 5 years. J Rheumatol 1995;22:1037-42.

7. Dellhag B, Bjelle A. A five-year followup of hand function and activities of daily living in rheumatoid arthritis patients. Arthritis Care Res 1999;12:33-41.

8. Dellhag B, Hosseini N, Bremell $\mathrm{T}$, Ingvarsson PE. Disturbed grip function in women with rheumatoid arthritis. J Rheumatol 2001;28:2624-33.

9. Kessler S, Dieppe P, Fuchs J, Stuermer T, Guenther KP. Assessing the prevalence of hand osteoarthritis in epidemiological studies. The reliability of a radiological hand scale. Ann Rheum Dis 2000;59:289-92.

10. Kellgren JH, Lawrence JS. Epidemiology of chronic rheumatism. Philadelphia: FA Davis, 1963.

11. Kallman DA, Wigley FM, Scott WW Jr, Hochberg MC, Tobin JD. New radiographic grading scales for osteoarthritis of the hand. Reliability for determining prevalence and progression. Arthritis Rheum 1989;32:1584-91.

12. Altman RD, Hochberg M, Murphy W, Wolfe F, Lequesne M. Atlas of individual radiographic features in osteoarthritis. Osteoarthritis Cartilage 1995;3(Suppl):3-70.

13. Verbruggen G, Veys EM. Numerical scoring systems for the anatomic evolution of osteoarthritis of the finger joints. Arthritis Rheum 1996;39:308-20.

14. Verbruggen G, Veys EM. Erosive and non-erosive hand osteoarthritis. Use and limitations of two scoring systems. Osteoarthritis Cartilage 2000;8(Suppl): S45-55.

15. Spector T D, Cooper C. Radiographic assessment of osteoarthritis: Whither, Kellgren and Lawrence? Osteoarthritis and Cartilage 1993 (in press).

16. Altman R, Alarcon G, Appelrouth D, et al. The American College of Rheumatology criteria for the classification and reporting of osteoarthritis of the hand. Arthritis Rheum 1990; 33: 1601-10.

17. Kellgren J H, Lawrence J S. Radiological assessment of osteoarthritis. Ann Rheum Dis 1957; 16: 494-501.

18. Hart DJ, Spector TD. The relationship of obesity, fat distribution and osteoarthritis in women in the general population: the Chinford study. J Rheumatol 1993; 20: 331-5.

19. Kallman D A, Wigley F M, Scott W W, Hochberg M C, Tobin J D. New radiographic grading scales for osteoarthritis of the hand. Arthritis Rheum 1989;32:158491.

20. Livshits G, Kalichman L, Cohen Z, Kobyliansky E. Mode of inheritance of hand osteoarthritis in ethnically homogeneous pedigrees. Hum Biol 2002;74:849-60.

21. Onat A, Sansoy V, Uysal O. Waist circumference and waist-tohip ratio in Turkish adults: interrelation with other risk factors and association with cardiovascular disease. Int J Cardiol 1999;70:43-50.

22. Empana JP, Ducimetiere P, Charles MA, Jouven X. Sagittal abdominal diameter and risk of sudden death in asymptomatic middle-aged men: the Paris Prospective Study I. Circulation 2004;110:2781-5. 